\title{
Number of conceptuses in utero affects porcine fetal muscle development
}

\author{
S C Town ${ }^{1}$, C T Putman ${ }^{1,2}$, N J Turchinsky ${ }^{1}$, W T Dixon ${ }^{1}$ and G R Foxcroft ${ }^{1}$ \\ ${ }^{1}$ Swine Reproduction-Development Program, Department of Agricultural, Food and Nutritional Science, University \\ of Alberta, Edmonton, AB, Canada, T6G $2 P 5$ and ${ }^{2}$ Exercise Biochemistry Laboratory, Faculty of Physical Education \\ and the Centre for Neuroscience, Faculty of Medicine and Dentistry, University of Alberta, Edmonton, AB, Canada, \\ T6G $2 \mathrm{H} 9$
}

Correspondence should be addressed to G R Foxcroft; Email: george.foxcroft@ualberta.ca

\begin{abstract}
Unmodified, third parity, control sows $(C T R ; n=30)$ or sows subjected to unilateral oviduct ligation before breeding (LIG; $n=30$ ), were slaughtered at either day 30 or day 90 of gestation and used to determine the effects of numbers of conceptuses in utero on prenatal, and particularly muscle fibre, development. Ovulation rate, number of conceptuses in utero, placental and fetal size, and (day 90 sows) fetal organ and semitendinosus muscle development were recorded. Tubal ligation reduced $(P<0.05)$ the number of viable embryos at day 30 and fetuses at day 90 . Placental weight at day 30 and day 90 , and fetal weight at day 90, were lower $(P<0.05)$ in CTR sows. All body organs except the brain were lighter, and the brain:liver weight ratio was higher in CTR fetuses $(\boldsymbol{P}<0.05)$, indicative of brain sparing and intrauterine growth restriction in fetuses from CTR sows. Muscle weight, muscle cross-sectional area and the total number of secondary fibres were also lower $(P<0.05)$ in CTR fetuses. The number of primary fibres, the secondary:primary muscle fibre ratio, and the distribution of myosin heavy chain$I \beta$, -Ila, fetal and embryonic isoforms did not differ between groups. Thus, even the relatively modest uterine crowding occurring naturally in CTR sows negatively affected placental and fetal development and the number of secondary muscle fibres. Consequences of more extreme crowding in utero on fetal and postnatal development, resulting from changing patterns of early embryonic survival, merit further investigation.

Reproduction (2004) 128 443-454
\end{abstract}

\section{Introduction}

In a species domesticated for commercial meat production like the pig, both the developmental competence and number of offspring born are critical. Earlier studies of uterine crowding in the gilt suggested that when the number of embryos exceeded 14, intrauterine crowding is a limiting factor for litter size born (Dziuk 1968), and Bazer et al. $(1969 a, b)$ suggested that increased embryonic loss was due to maternal limitations (uterine capacity) and not to inherent limitations of the embryo. Although competition among embryos in the pre-implantation period may reduce within-litter variation in development by selectively removing the least developed embryos (van der Lende et al. 1990), uterine capacity can affect both litter size and the average birth weight of the litter, even in gilts with 'normal' ovulation rates (Père et al. 1997).

Days 30 to 40 of gestation are the critical period when uterine capacity exerts its effects (Fenton et al. 1970, Knight et al. 1977, Vallet 2000). Furthermore, Vallet et al. (2003) suggested that fetal growth rate is less sensitive to intrauterine crowding than placental growth rate and that, as in the prolific Meishan female (Ford \& Youngs 1993), an increase in placental efficiency may initially protect the developing fetus from a limitation in placental size. However, conclusions based only on a consideration of fetal weight may overlook critical effects on fetal development established early in gestation.

The pathology of 'runted' or intrauterine growth retarded (IUGR) offspring has been described previously in the pig (Adams 1971, Widdowson 1971, Cooper et al. 1978, Hegarty \& Allen 1978, Flecknell et al. 1981), and effects on the developmental potential of IUGR pigs could not be entirely explained on the basis of their lower birth weight (van der Lende \& de Jager 1991). Furthermore, the extent of within-litter IUGR was already established at days 27 to 35 of gestation and the largest litters in utero generally included one or more IUGR fetuses (van der Lende et al. 1990).

Pre-implantation embryonic losses are still considered to be the largest proportion of prenatal loss in the pig (see 
Ashworth \& Pickard 1998), and in commercial practice this generalisation likely reflects the situation in gilts and in weaned, first parity, sows. However, the dynamics of prenatal loss in some dam-line populations may be changing and Foxcroft (1997) suggested that several generations of selection for prolificacy may have increased the discrepancy between ovulation rate and the number of conceptuses surviving post-implantation, and uterine capacity. Even in gilts, embryonic survival rate to day 28 of gestation can be $100 \%$ in individuals with $>20$ ovulations, and the number of conceptuses in utero at day 28 was inversely related to placental volume (Almeida et al. 2000). In higher parity females, the situation may be even more extreme. Although embryonic survival to day 25 to 30 of gestation across three studies in commercial damline sows was only around $60 \%$, mean ovulation rates of $26.9 \pm 1.4$ (Orzechowski 1998), $26.6 \pm 0.4$ (Vonnahme et al. 2002) and $24.7 \pm 0.4$ (Town 2004) resulted in 16.4, 15.8 and around 15.0 embryos in utero respectively, between days 25 and 30 of gestation. At this stage the number of conceptuses in utero was again negatively related to placental size and a proportion of these conceptuses were then lost before days 50 to 55 of gestation (Vonnahme et al. 2002, Town 2004). Although 'functional' uterine capacity may increase in higher parity sows (Town 2004), it is still likely that the number of surviving embryos initially exceeds functional uterine capacity in a substantial proportion of these sow herds.

Although uterine crowding and reduced placental size did not affect the size and weight of the embryo in the immediate post-implantation period (Almeida et al. 2000, Vonnahme et al. 2002, Town 2004), potential impacts on fetal development need careful study. If the placental compensatory mechanisms described by Biensen et al. (1998) are not adequate, crowding may still affect fetal development. This raises important questions for both fetal and postnatal development, particularly with respect to the development of fetal muscle fibres, which start to differentiate around day 35 of gestation in the pig (Wigmore \& Stickland 1983). Therefore, in contrast to situations in which IUGR is limited to a discrete subpopulation of 'runt' fetuses (Royston et al. 1982, Wooton et al. 1983), we hypothesize that a pattern of prenatal loss that results in uterine crowding in the post-implantation stage of gestation will produce a more uniform effect on placental and fetal development.

Dwyer et al. (1992) suggested that a reduction in placental size might be the mechanism mediating negative effects of maternal undernutrition on birth weight and the number of secondary muscle fibres in the offspring (Handel \& Stickland 1987, Dwyer et al. 1994). Consistent with the earlier data of Hegarty and Allen (1978) indicating that runts have reduced muscle growth potential and needed 23 days longer to reach a weight of approximately $105 \mathrm{~kg}$, Dwyer et al. (1993) established a positive correlation between the total number of muscle fibres and postnatal growth potential. Furthermore, the effect of maternal nutrition was identified as occurring between days 25 and 50 of gestation, the period immediately preceding secondary muscle fibre hyperplasia (Dwyer et al. 1994). This, and the more recent study of Clelland and Stickland (2001), led to the central hypothesis tested in the present study, that, 'by detrimentally affecting placental size in early gestation, uterine crowding will also affect fetal organ development and the number and type of muscle fibres, analogous to the situation of IUGR in nutritionally challenged sows'. Preliminary data from an initial experiment supported this hypothesis, in that even when the number of conceptuses in utero did not affect birth weight, 'crowding' nevertheless resulted in measurable IUGR in the fetus (Town et al. 2002). The present study evaluated an alternative experimental approach to test further this central hypothesis.

\section{Materials and Methods Animals}

The experiment was conducted at the Swine Research and Technology Centre at the University of Alberta, in accordance with the guidelines of the Canadian Council for Animal Care and under authorisation from the University of Alberta Animal Policy and Welfare Committee (approval \# 200134D). Sixty Hybrid F1 third parity sows (Genex Swine Group, Regina, Saskatchewan, Canada) were housed in a controlled environment barn, managed and fed as per standard protocols during gestation and lactation and were weaned at 23 days after farrowing. Average sow body weight and back fat measurements at postweaning oestrus were $210 \pm 2.01 \mathrm{~kg}$ and $17.4 \pm 0.33 \mathrm{~mm}$ respectively. Sows were randomly allocated to one of two groups. The experimental group $(n=30)$ underwent unilateral oviduct ligation surgery (LIG) approximately 3 days after the end of their first post-weaning oestrus. The purpose of this surgery was to reduce the number of embryos in utero by preventing the oocytes ovulated from the ovary ipsilateral to the ligated oviduct from being fertilised and entering the uterus. The remaining animals $(n=30)$ did not undergo surgery and formed the control group (CTR). Half the animals from each group were killed at day 30 of gestation to determine the number of conceptuses in utero. The remaining animals were killed at day 90 of gestation to determine the effects of crowding on fetal development. Day 90 was chosen since total number of muscle fibres is considered to be definitively established by approximately day 90 in the pig (Wigmore \& Stickland 1983). Anaesthesia was induced using an intravenous short acting general anaesthetic (5\% solution of sodium thiopental, Pentothal, Merial Ltd, Iselin, NJ, USA; dosage $6.6 \mathrm{ml} \mathrm{kg}^{-1}$ body weight) via an ear vein. Anaesthesia was maintained with a closed circuit system of inhalation of the general anaesthetic halothane (Fluothane), in combination with nitrous oxide and oxygen via a facemask. Post surgical care was provided using approved procedures. 


\section{Heat checking and breeding}

All sows were bred by artificial insemination at their second post-weaning oestrus. Heat detection was carried out every $12 \mathrm{~h}(0700$ and $1900 \mathrm{~h})$ using the back pressure test during periods of fence-line contact with a mature vasectomised boar starting on day 18 of the oestrous cycle. All sows were bred by artificial insemination using pooled semen from the same group of three fertile boars, using 3 billion sperm per dose, at $12 \mathrm{~h}$ and $36 \mathrm{~h}$ after the onset of standing heat and then every $24 \mathrm{~h}$ until the animals were no longer in standing heat (i.e. $12 \mathrm{~h}, 36 \mathrm{~h}, 60 \mathrm{~h}$ etc.). Signs of a return to oestrus were recorded between days 18 and 22 post-insemination and pregnancy was confirmed at day 25 of gestation using real time ultrasound (RTU).

\section{Slaughter and necropsy procedure}

Sows were shipped to a local abattoir and reproductive tracts were recovered and dissected within $1 \mathrm{~h}$ after slaughter. Ovulation rate and the number of viable embryos or fetuses in utero were recorded for all sows. At day 30 of gestation, embryonic and placental weights were also measured. At day 90, fetal and placental weights were recorded and all fetuses were necropsied to determine various body organ weights including the brain, heart, lungs, liver, kidneys and spleen. After removal and weighing of the internal organs, the empty carcass was also weighed. The brain:liver weight ratio was then used as an estimate of disproportionate changes in organ development, indicative of the occurrence of IUGR. Results were averaged within litter. Relative piglet organ weights (actual organ weight divided by the actual body weight) were also calculated to further examine the pattern of organ growth in fetuses with different body weights. Again the average measurement from each litter was used for analysis. Two day-90 fetuses closest to the mean body weight within each litter were chosen for removal of the semitendinosus muscles, which were dissected, weighed, mounted on aluminium foil in a slightly stretched position and frozen in melting isopentane cooled in liquid nitrogen $\left(-156^{\circ} \mathrm{C}\right)$. Samples were stored at $-80^{\circ} \mathrm{C}$ until used for immunohistochemical and electrophoretic analyses.

\section{Antibodies}

Table 1 lists the monoclonal antibodies directed against various myosin heavy chain (MHC) isoforms used in this study.

\section{Immunohistochemical staining}

Serial sections $(10 \mu \mathrm{m})$ of fetal day 90 semitendinosus muscle were collected on poly-L-lysine-coated slides (Electron Microscopy Sciences, Fort Washington, PA, USA) and stored at $-80^{\circ} \mathrm{C}$ for later analysis. Adult triceps brachii tissue was also collected to confirm reactivity of the antibodies with porcine tissue. Frozen muscle sections were air-dried, washed once in phosphate-buffered saline with $0.1 \%(\mathrm{v} / \mathrm{v})$ Tween 20 (PBS-Tween), twice in PBS, and incubated for $15 \mathrm{~min}$ in $3 \%(\mathrm{v} / \mathrm{v}) \mathrm{H}_{2} \mathrm{O}_{2}$ in methanol. The avidin-biotin-peroxidase technique (Vectastain Elite $\mathrm{ABC}$ kit, Vector Laboratories, Burlingame, CA, USA) was used to visualise immunoreactivity according to the manufacturer's protocol with modifications according to Putman et al. (2003) and using the antibody dilutions in Table 1.

Table 1 Antibodies and their respective dilutions in immunohistochemistry (IHC) and In-Gel immunodetection (IG) assays.

\begin{tabular}{|c|c|c|c|}
\hline \multirow[b]{2}{*}{ Reagents } & \multicolumn{2}{|c|}{ Assay } & \multirow[b]{2}{*}{ Source/Reference } \\
\hline & $\mathrm{IHC}^{\mathrm{b}}$ & IG & \\
\hline Anti-MHC (all isoforms) (MF-20) ${ }^{\mathrm{a}}$ & Not used & $1: 10$ & Developmental Studies Hybridoma Bank, University of lowa, Ames, IO, USA \\
\hline Anti-MHCI $(\mathrm{NOQ7.5.4D)}$ & 1:4000 & $1: 7000$ & Sigma-Aldrich, St Louis, MO, USA \\
\hline Anti-MHCI $\beta(B A-D 5)^{a}$ & $1: 100$ & Not used & Schiaffino et al. (1989) \\
\hline Anti-MHC1 $\alpha(\mathrm{F} 88.12 \mathrm{~F} 8)$ & $1: 10$ & Not used & Biocytex, Marseilles, France \\
\hline $\begin{array}{l}\text { Anti-MHC (developmental and all } \\
\text { fast forms) (MY-32) }\end{array}$ & $1: 1000$ & $1: 160000$ & Sigma-Aldrich \\
\hline Anti-MHClla $(\text { SC-71) })^{\mathrm{a}}$ & $1: 50$ & $1: 200$ & Schiaffino et al. (1989) \\
\hline Anti-MHCIlb (BF-F3) ${ }^{\mathrm{a}}$ & $1: 50$ & $1: 200$ & Schiaffino et al. (1989) \\
\hline $\begin{array}{l}\text { Anti-MHC (all isoforms except } \\
\text { MHClld(x) (BF-35) }\end{array}$ & $0.1 \mu \mathrm{g} / \mathrm{ml}$ & $1: 1000$ & Schiaffino et al. (1989) \\
\hline Anti-MHC (embryonic) (BF-45) & $1: 1000$ & $1: 2000$ & Schiaffino et al. (1988) \\
\hline Anti-MHC (embryonic) (NCL-d $)^{a}$ & $1: 20$ & $1: 40$ & Novocastra Laboratories, Newcastle, UK \\
\hline Anti-MHC (neonatal) (NCL-n) ${ }^{\mathrm{a}}$ & $1: 10$ & $1: 20$ & Novocastra Laboratories \\
\hline $\begin{array}{l}\text { Anti-mouse IgG (biotinylated) } \\
\text { (raised in horse - rat pre-adsorbed } \\
\text { and affinity purified) }\end{array}$ & $1: 500$ & $1: 500$ & Vector Laboratories, Burlingame, CA, USA \\
\hline $\begin{array}{l}\text { Anti-mouse IgM (biotinylated) } \\
\text { (used with BF-F3) }\end{array}$ & $1: 500$ & $1: 500$ & Vector Laboratories \\
\hline Normal mouse IgG (control serum) & $1: 2000$ & Not used & Santa Cruz Biochemical, Santa Cruz, CA, USA \\
\hline
\end{tabular}

${ }^{a}$ Hybridoma culture supernatant; ${ }^{b}$ for immunohistochemistry, a blocking solution containing horse serum (BS-1) was used for all dilutions of IgG antibodies while a goat serum-containing blocking solution (BS-2) was used in the dilutions of BF-F3 (IgM). 
Control sections were processed in parallel incubations in which the primary antibody was omitted or substituted with non-specific control mouse IgG. After dehydration in ethanol, sections were cleared with xylene and mounted with Entellan (Merck, Darmstadt, Germany).

Image acquisition was carried out using a motorised scanning stage Zeiss Axioplan IIM Universal Microscope (Carl Zeiss Jena GmbH, Jena, Germany) and a Photometrics CoolSNAP HQ Camera (Roper Scientific, Tucson, AZ, USA) in conjunction with the Metamorph Imaging System (Universal Imaging Corporation, Downingtown, PA, USA). Images of the entire cross section of each muscle were obtained and saved to CD in montage format for Metamorph Image analysis. Serial sections of day 90 tissue stained for the various $\mathrm{MHC}$ isoforms were examined to determine which muscle fibre isoforms were present. Sections stained with the NOQ7.5.4D antibody (anti-MHCI $\beta$ ) were used to determine semitendinosus muscle total cross-sectional area (CSA), muscle fibre type (i.e. primary or secondary), and fibre CSA. Two distinct areas of the muscle were examined. For each individual muscle, five fields were selected at random from the deep red portion and five from the superficial white portion of the muscle. Results from both portions of the muscle were averaged, and the resulting 10 fields per muscle encompassed a total area of $1.48 \mathrm{~mm}^{2}$. An average of $10410 \pm 981$ fibres (mean \pm S.D.) were examined per muscle. Mean CSA of primary and secondary fibres was measured from at least 300 fibres of each type. Total numbers of primary and secondary fibres were calculated for each muscle by extrapolating the mean number of fibres of each type per $\mathrm{mm}^{2}$ to the actual CSA of the entire semitendinosus muscle determined by measurement using the Metamorph Imaging System. Two piglets were analysed per litter and the results were averaged within sow to examine the effects of uterine crowding on muscle fibre development.

\section{Myosin extraction}

Frozen muscles were pulverised and the myosin fraction was extracted according to the protocols of Putman et al. (2003). Protein concentrations were determined using the Bradford procedure (Bio-Rad Laboratories, Hercules, CA, USA).

\section{Standard sodium dodecylsulphate-polyacrylamide gel electrophoresis (SDS-PAGE)}

The MHC complement of whole muscle extracts was analysed by SDS-PAGE using a slightly modified version of the method described by Hämäläinen and Pette (1996), which has been described elsewhere (Putman et al. 2003). $\mathrm{MHC}$ isoforms were separated at $10^{\circ} \mathrm{C}$ for $24 \mathrm{~h}$ at $275 \mathrm{~V}$ (constant voltage) and visualised by silver staining. The relative $\mathrm{MHC}$ isoform contents were quantified densitometrically using the Syngene Chemigenius gel documentation system and GeneTools gel analysis software
(Syngene, Cambridge, Cambs, UK). The scheme used for identifying the various MHC isoforms was validated by In-Gel immunodetection and by comparison with rodent muscles.

\section{In-Gel immunodetection}

In-Gel immunodetection of the various MHC isoforms was carried out using the Unblot In-Gel Chemiluminescent Detection Kit for Biotinylated Antibody Probes (Pierce Biotechnology, Rockford, IL, USA). Following standard SDS-PAGE, gels were pretreated with 50\% (v/v) isopropyl alcohol and then washed in ultrapure water. Gels were then reacted for $1 \mathrm{~h}$ at room temperature with monoclonal antibodies against various $\mathrm{MHC}$ isoforms at the dilutions indicated in Table 1 and processed with the appropriate biotinylated secondary antibody (biotinylated horse antimouse IgG or biotinylated goat anti-mouse IgM (BF-F3)) and streptavidin-horse radish peroxidase according to the manufacturer's protocol. The gel was then placed between two cellophane sheets and exposed to a charge-coupled device camera to detect the chemiluminescent signal using the Syngene Chemigenius gel documentation system (Syngene).

\section{Statistical analysis}

To determine the effects of treatment on ovulation rate, number of viable embryos, embryonic survival rate, placental and embryo/fetal weights, placental efficiency, fetal organ weights, fetal brain:liver weight ratio, muscle weight and CSA, fibre number, secondary:primary fibre ratio and $\mathrm{MHC}$ isoform distribution, data were analysed as appropriate for a completely randomised design. Sow was used as the experimental unit for analysis, and fetal weights, placental weights, organ and muscle parameters were averaged within each reproductive tract (sow) before analysis. Data were analysed using the General Linear Model (GLM) procedure of the Statistical Analysis System (SAS 1990, SAS Inst. Inc., Cary, NC, USA). The model included treatment group (CTR or LIG). Significance was considered as $P<0.05$. The results are presented as means \pm S.E.M. Important associations among characteristics measured were examined across treatment groups using correlation analysis (INSIGHT procedure; SAS 1990). These included relevant correlations within gestational age between number of viable embryos/fetuses, embryo/fetal weight, placental weight, fetal organ weights (day 90) and brain:liver weight ratio.

\section{Results \\ General results}

Of the 60 sows slaughtered, 58 were confirmed pregnant by the presence of viable conceptuses. Removals from final analysis were due to missing data as a result of damage during tract removal and tissue collection (missing ovaries, etc). Overall ovulation rate for this sow population 
Table 2 Reproductive characteristics (means \pm S.E.M.) of control (CTR) and unilaterally oviduct ligated (LIG) sows $(n=59)$.

\begin{tabular}{|c|c|c|c|}
\hline \multirow[b]{2}{*}{ Parameter } & \multicolumn{2}{|c|}{ Treatment group } & \multirow[b]{2}{*}{$\boldsymbol{P}$} \\
\hline & CTR $(n=30)$ 'Relatively crowded' & LIG $(n=29)$ 'Non-crowded' & \\
\hline Overall ovulation rate & $19.2 \pm 0.5(n=30)$ & $20.6 \pm 0.5(n=28)$ & 0.054 \\
\hline Ovulation rate available for fertilization & $19.2 \pm 0.5$ & $10.5 \pm 0.6$ & $<0.001$ \\
\hline Number of sows at day $30(n)$ & 15 & 15 & \\
\hline Number of viable embryos (day 30) & $15.1 \pm 0.8$ & $9.3 \pm 0.8$ & $<0.001$ \\
\hline Embryonic survival to day $30(\%)$ & $79 \pm 3$ & $91 \pm 2$ & 0.006 \\
\hline Average placental weight $(\mathrm{g})$ at day 30 & $19.2 \pm 1.0$ & $26.2 \pm 1.4$ & $<0.001$ \\
\hline Average embryo weight $(\mathrm{g})$ at day 30 & $1.15 \pm 0.05$ & $1.22 \pm 0.05$ & 0.34 \\
\hline Placental efficiency at day 30 & $0.071 \pm 0.005$ & $0.050 \pm 0.003$ & 0.001 \\
\hline Number of sows at day $90(n)$ & 15 & 14 & \\
\hline Number of viable fetuses (day 90) & $14.4 \pm 0.5$ & $9.4 \pm 0.7$ & $<0.001$ \\
\hline Fetal survival to day $90(\%)$ & $76 \pm 3$ & $84 \pm 3$ & 0.029 \\
\hline Average placental weight (g) at day 90 & $219 \pm 8$ & $274 \pm 14$ & 0.003 \\
\hline Average fetal weight (g) at day 90 & $588 \pm 18$ & $679 \pm 18$ & 0.002 \\
\hline Placental efficiency at day 90 & $2.84 \pm 0.09$ & $2.64 \pm 0.12$ & 0.20 \\
\hline
\end{tabular}

was $19.90 \pm 0.36$. Data derived from dissection of reproductive tracts at day 30 and day 90 are presented in Table 2. In addition to an unexpected and marginal difference in ovulation rate between CTR $(19.23 \pm 0.48)$ and LIG $(20.61 \pm 0.50)$ sows, ovulation rate available for fertilisation was substantially reduced by the ligation procedure. As a consequence, both the number of viable embryos at day 30 and the number of fetuses at day 90 differed between treatments. Embryo survival to day 30 and fetal survival to day 90 were both higher in the LIG group.

Average placental weight was lighter in CTR animals at day 30 and day 90 of gestation. Average embryo weight was not different between groups at day 30; however, average fetal weights at day 90 were lighter in CTR sows. Placental efficiency, calculated as the embryo weight:placental weight ratio, was higher in the CTR group at day 30; however, this relationship was lost in the day 90 fetuses in which placental efficiency was not different between the two groups.

Average placental weight was positively correlated with average embryo weight at day 30 of gestation $(r=0.56$; $P<0.01$; Fig. 1a) and with average fetal weight at day 90 of gestation ( $r=0.68 ; P<0.01$; Fig. 1b). Furthermore, average placental weight was negatively correlated with the number of viable embryos at day $30 \quad(r=-0.61$; $P<0.01$; Fig. 2a) and the number of viable fetuses at day $90 \quad(r=-0.67 ; \quad P<0.01 ;$ Fig. 2b). Although average embryo weight was not correlated with the number of viable embryos at day 30, a negative relationship was established between the number of fetuses and fetal weight at day $90(r=-0.61 ; P<0.01$; Fig. 3$)$.

Placental efficiency was not correlated with average embryonic or fetal weight at either day 30 or day 90 of gestation, although it was weakly correlated with the number of viable embryos at day $30(r=0.37 ; P<0.05)$ and the number of viable fetuses at day $90 \quad(r=0.35$; $P=0.06$ ). However, placental efficiency showed a strong negative correlation with average placental weight
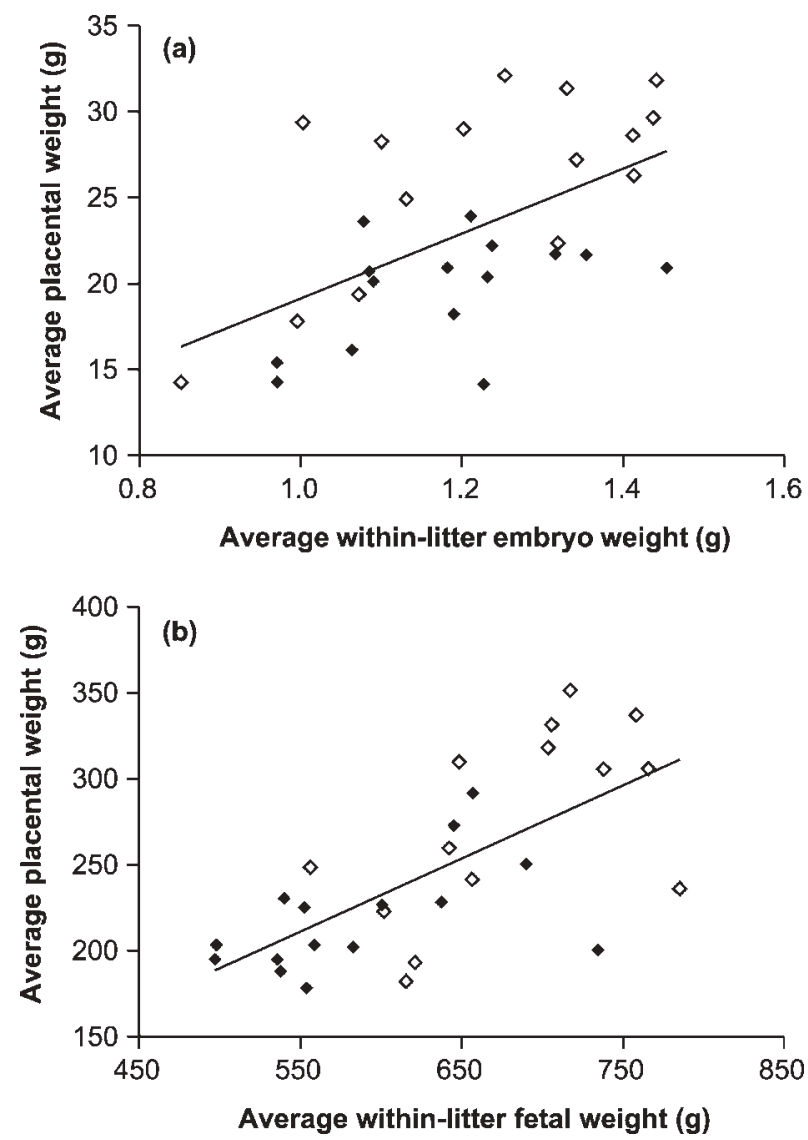

Figure 1 Correlation between average placental weight and (a) average within-litter embryo weight at day 30 of gestation $\left(r^{2}=0.31\right.$; $P=0.0014)$ and (b) average within-litter fetal weight at day 90 of gestation $\left(r^{2}=0.46 ; P<0.0001\right)$ in LIG animals $(\diamond)$ and CTR animals $(\diamond)$.

at day $30 \quad(r=-0.65 ; \quad P<0.0001)$ and day 90 $(r=-0.75 ; P<0.0001)$.

\section{Day 90 necropsy data}

Fetal organ weight data at day 90 of gestation are shown in Table 3. The brain was the only organ for 

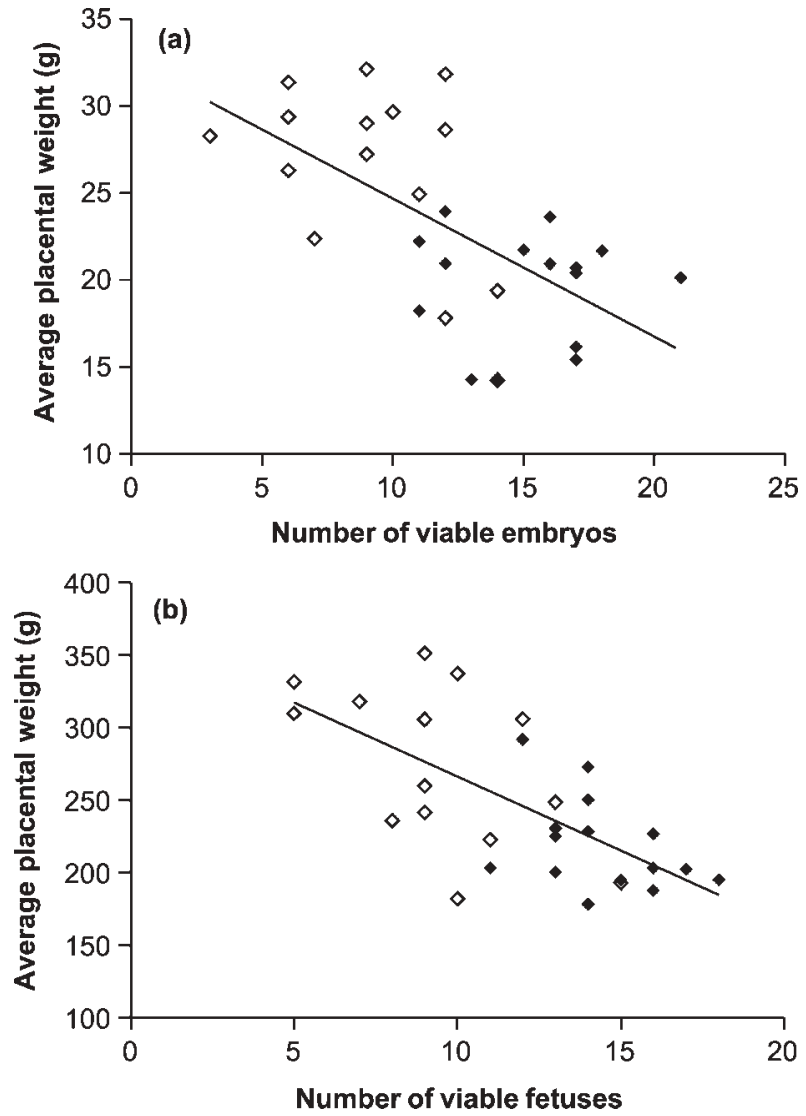

Figure 2 Correlation between average placental weight and (a) number of viable embryos at day 30 of gestation $\left(r^{2}=-0.37\right.$; $P=0.0003$ ) and (b) number of viable fetuses at day 90 of gestation $\left(r^{2}=-0.45 ; P<0.0001\right)$ in LIG animals $(\diamond)$ and CTR animals $(\diamond)$.

which there was no difference between treatments. All other organs were heavier in fetuses from LIG sows $(P<0.05)$. Furthermore, the brain:liver weight ratio was higher in the fetuses from CTR litters, and the brain: semitendinosus muscle weight ratio and the ratio of the brain:total number of secondary muscle fibres, were also higher in the CTR sows.

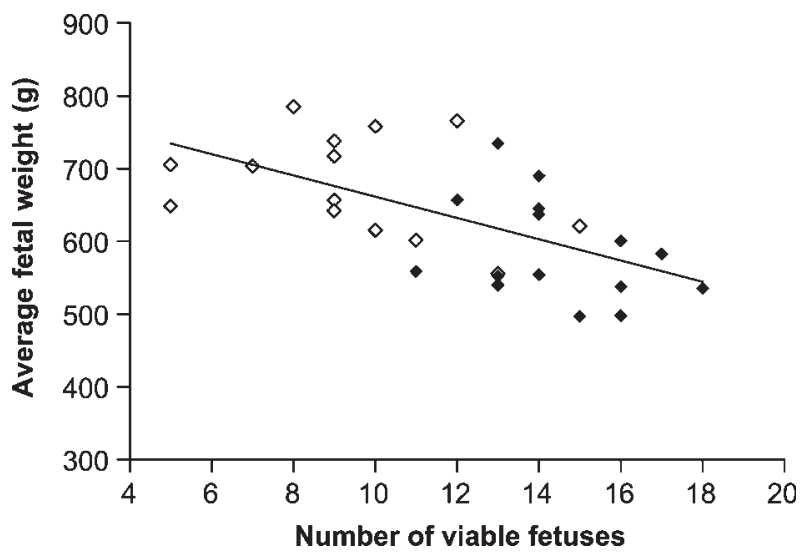

Figure 3 Correlation between average fetal weight and number of viable fetuses at day 90 of gestation $\left(r^{2}=-0.37 ; P=0.0005\right)$ in LIG animals $(\diamond)$ and CTR animals $(\diamond)$.
Table 3 Average empty carcass and body organ weights and brain:organ weight ratios (means \pm S.E.M.) in fetuses from control (CTR) and unilaterally oviduct ligated (LIG) sows at day 90 of gestation.

\begin{tabular}{|c|c|c|c|}
\hline \multirow[b]{2}{*}{ Parameter } & \multicolumn{2}{|c|}{ Treatment group } & \multirow[b]{2}{*}{$\boldsymbol{P}$} \\
\hline & $\begin{array}{c}\text { CTR }(n=15) \\
\text { 'Relatively crowded' }\end{array}$ & $\begin{array}{l}\text { LIG }(n=14) \\
\text { 'Non-crowded' }\end{array}$ & \\
\hline Spleen (g) & $0.84 \pm 0.04$ & $1.07 \pm 0.09$ & 0.015 \\
\hline Liver (g) & $17.81 \pm 0.63$ & $21.48 \pm 0.94$ & 0.003 \\
\hline Heart (g) & $4.09 \pm 0.15$ & $4.65 \pm 0.15$ & 0.013 \\
\hline Lungs (g) & $17.55 \pm 0.64$ & $19.61 \pm 0.64$ & 0.031 \\
\hline Kidneys (g) & $6.33 \pm 0.18$ & $7.35 \pm 0.25$ & 0.002 \\
\hline Brain $(g)$ & $19.65 \pm 0.33$ & $20.02 \pm 0.41$ & 0.48 \\
\hline Empty carcass (g) & $464.7 \pm 13.5$ & $536.4 \pm 14.3$ & 0.001 \\
\hline $\begin{array}{l}\text { Brain:liver } \\
\text { weight ratio }\end{array}$ & $1.17 \pm 0.04$ & $0.97 \pm 0.04$ & 0.002 \\
\hline $\begin{array}{l}\text { Brain:ST muscle } \\
\text { weight ratio }\end{array}$ & $10.49 \pm 0.43$ & $9.25 \pm 0.33$ & 0.031 \\
\hline $\begin{array}{l}\text { Brain:total } \\
\text { secondary fibre ratio }\end{array}$ & $(62 \pm 3.5)^{10^{-5}}$ & $(52 \pm 2.3)^{10^{-5}}$ & 0.021 \\
\hline
\end{tabular}

ST, semitendinosus.

Fetal weight was positively correlated to absolute weight of the fetal liver $(r=0.91 ; P<0.0001$; Fig. 4a), brain $(r=0.56 ; P<0.002$; Fig. 4b), heart $(r=0.91 ; P<0.0001)$, lungs $(r=0.81 ; P<0.0001)$, spleen $(r=0.67 ; P<0.0001)$
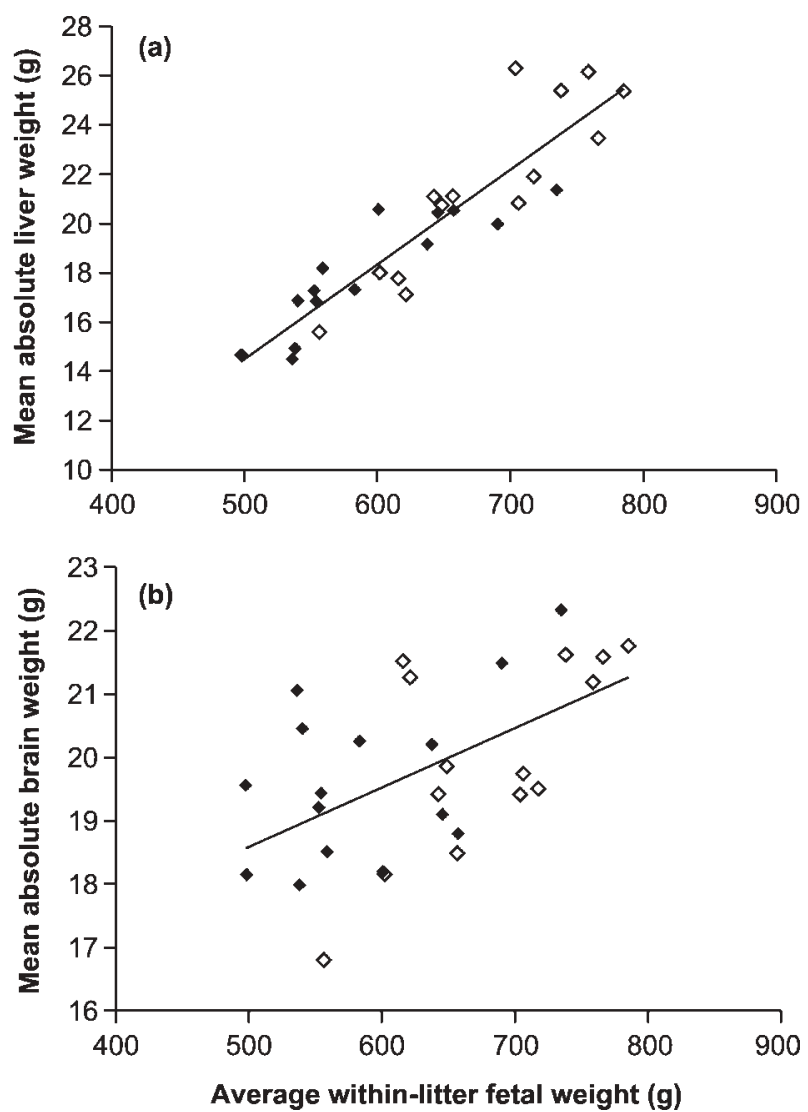

Figure 4 Correlation between (a) mean absolute liver weight $\left(r^{2}=0.83 ; P<0.0001\right)$ and (b) mean absolute brain weight $\left(r^{2}=0.31 ; P=0.0017\right)$ and average within-litter fetal weight at day 90 of gestation in LIG animals $(\diamond)$ and CTR animals $(\diamond)$. 

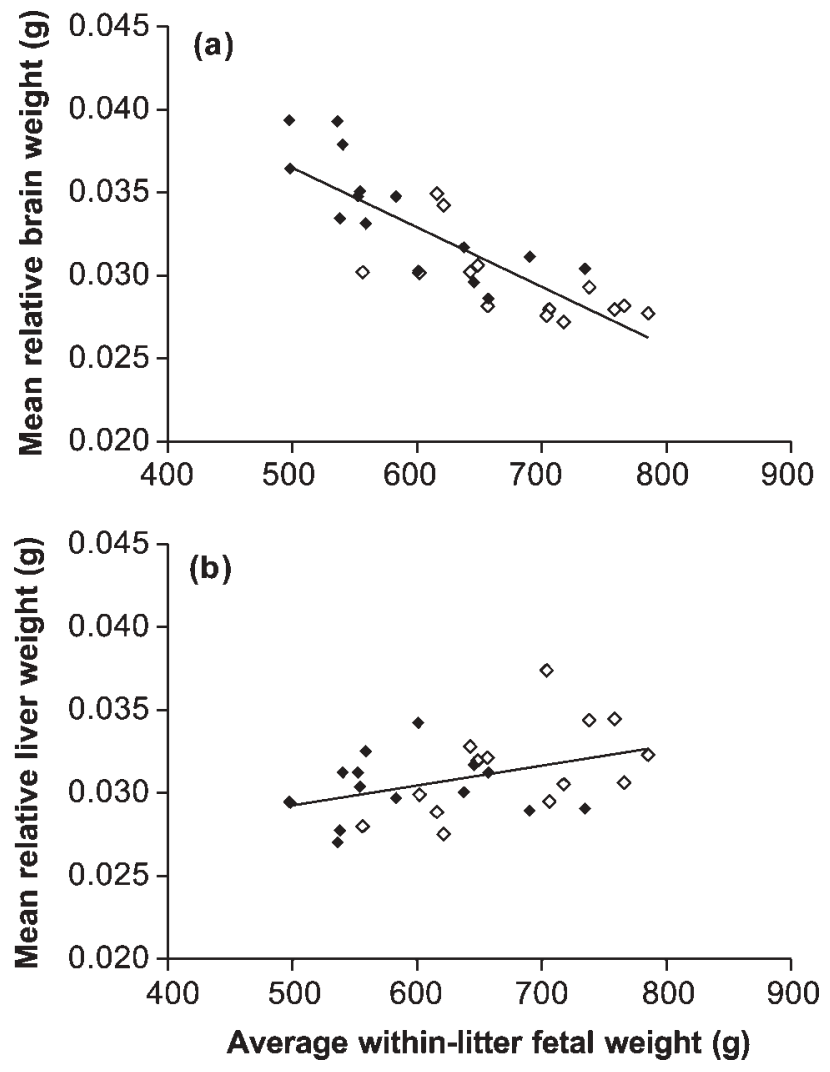

Figure 5 Correlation between (a) mean relative brain weight $\left(r^{2}=-0.68 ; P<0.0001\right)$ and $(b)$ mean relative liver weight $\left(r^{2}=0.18 ; P=0.0231\right)$ and average within-litter fetal weight at day 90 of gestation in LIG animals $(\diamond)$ and CTR animals $(\bullet)$.

and semitendinosus muscles $(r=0.79 ; P<0.0001)$ and to semitendinosus CSA $(r=0.74 ; P<0.0001)$. When relative organ weights were calculated as the absolute organ weight:body weight ratio, mean relative brain weight showed a strong negative correlation to mean fetal weight $(r=-0.82, P<0.0001$; Fig. 5a). In contrast, mean relative liver weight was only weakly correlated with average fetal weight $(r=0.42 ; P>0.05$; Fig. 5b), and no correlations were evident $(P \geq 0.1)$ with mean relative heart, lung, spleen and semitendinosus muscle weights and semitendinosus CSA. The mean brain:liver weight ratio was negatively correlated with mean fetal weight $(r=-0.76 ; P<0.0001$; Fig. 6a) and mean placental weight $(r=-0.74 ; P<0.0001$; Fig. $6 \mathrm{~b})$, but positively correlated to the number of viable fetuses ( $r=0.73 ; P<0.0001$; Fig. 7$)$.

\section{Immunohistochemical analysis}

\section{Myosin isoforms}

Immunohistochemistry results are shown in Fig. 8. For the day 90 fetal semitendinosus tissue, positive specific staining for $\mathrm{MHCl} \beta$ (NOQ7.5.4D and BA-D5), and MHClla (SC-71) was observed. MY-32 (all fast MHC) seemed to give a positive reaction with primary fibres in addition
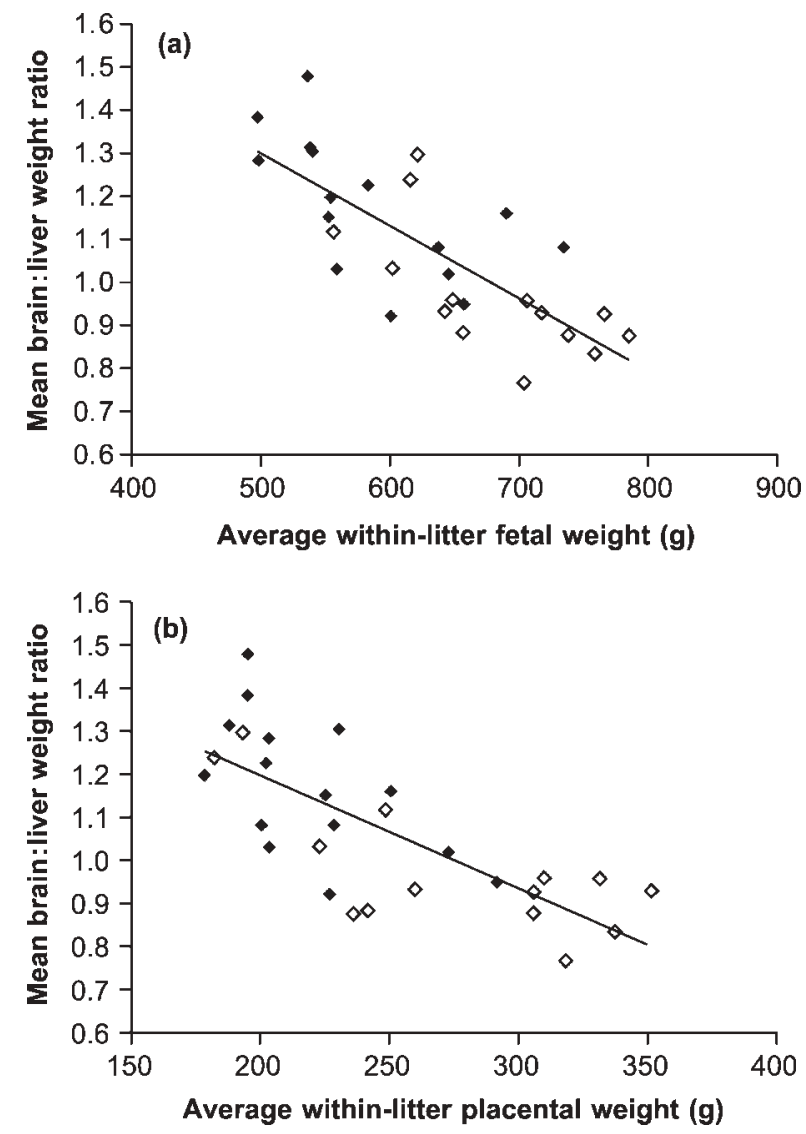

Figure 6 Correlation between mean brain:liver weight ratio and (a) average within-litter fetal weight $\left(r^{2}=-0.58 ; P<0.0001\right)$ and (b) average within-litter placental weight $\left(r^{2}=-0.55 ; P<0.0001\right)$ at day 90 of gestation in LIG animals $(\diamond)$ and CTR animals $(\diamond)$.

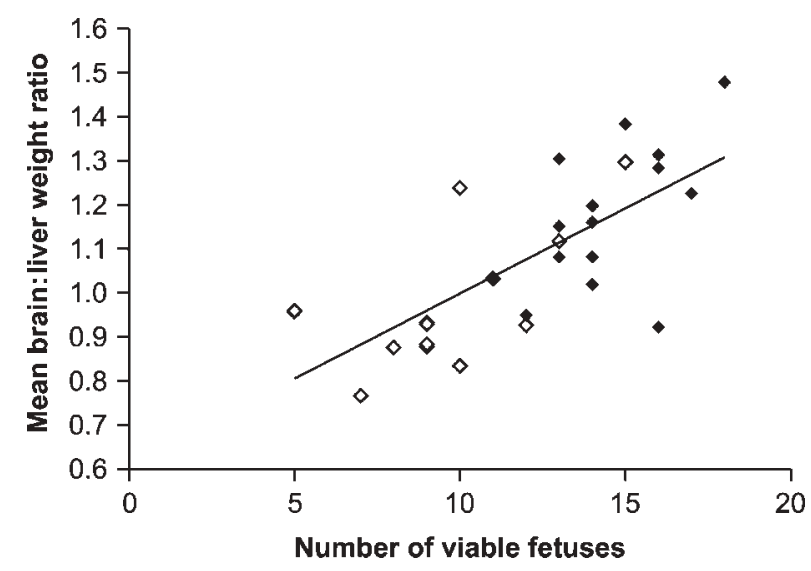

Figure 7 Correlation between mean brain:liver weight ratio and number of viable fetuses at day 90 of gestation $\left(r^{2}=0.53 ; P<0.0001\right)$ in LIG animals $(\diamond)$ and CTR animals $(\diamond)$.

to positively staining secondary muscle fibres in day 90 tissue. BF-35 (recognizing all MHC isoforms except for $\mathrm{MHClld}(\mathrm{x})$ ) resulted in staining of all fibres present, probably indicating that no $\mathrm{Id}(\mathrm{x})$ fibres are present at day 90 . No staining was observed for F88.12F8 (specific to 

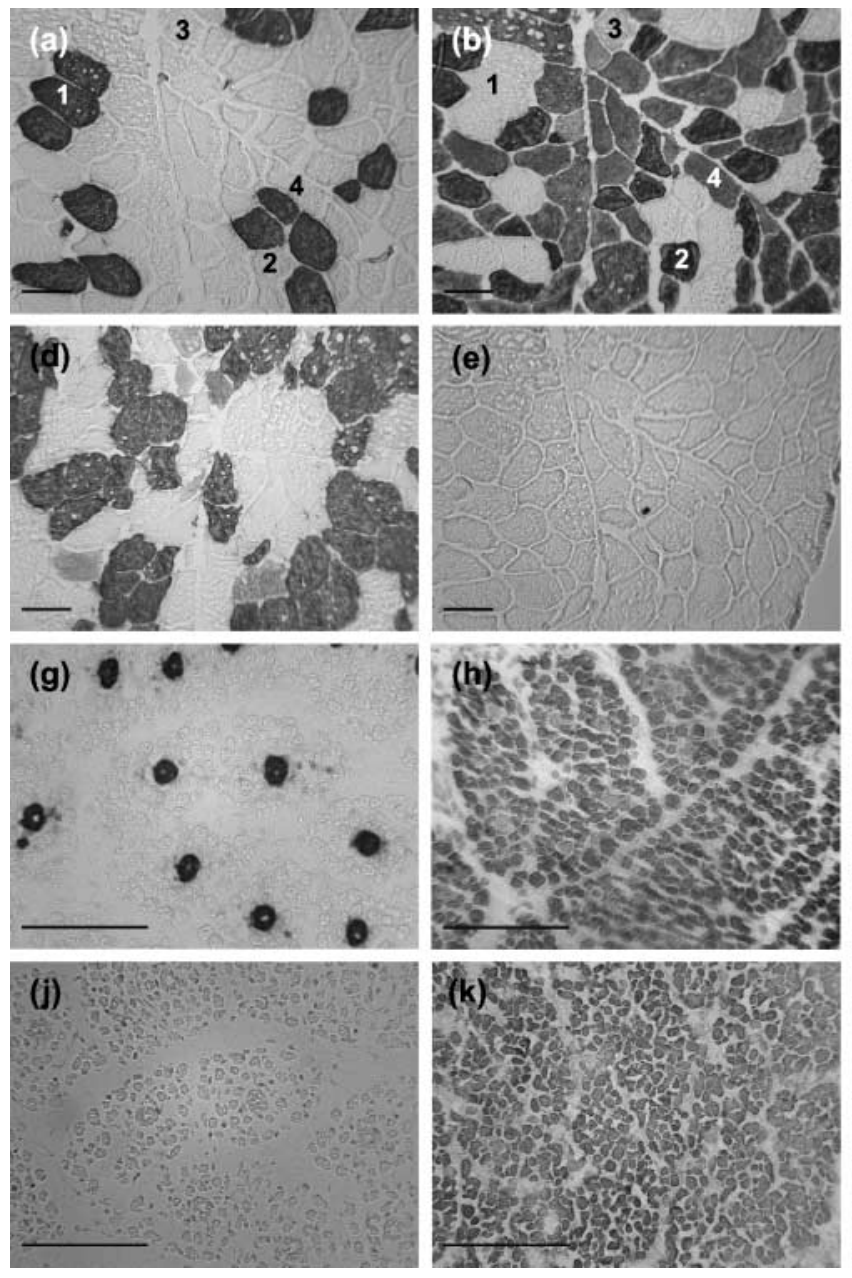

$\mathrm{MHCl} \alpha$; data not shown) or BF-F3 (specific to MHCllb). Surprisingly, a negative result was also obtained for the developmental antibodies NCL-d (anti-MHC embryonic), NCL-n (anti-MHC neonatal) and BF-45 (anti-MHC embryonic). In adult triceps brachii tissue, which was used to confirm reactivity of the antibodies used with pig tissue, positive staining was observed using NOQ7.5.4D, BA-D5, and SC-71 and, in contrast to the day 90 semitendinosus tissue, BF-35 did not stain all fibres, indicating the presence of pure $\mathrm{IId}(\mathrm{x})$ fibres. Additionally, positive staining was observed for BF-F3, indicating that $\mathrm{MHCllb}$ fibres are also present in adult tissue. F88.12F8 and MY-32 have previously been shown to react with swine MHCl $\alpha$ (Lefaucheur et al. 1995, 1997) and all fast MHC respectively (Fazarinc et al. 1995).

\section{Muscle fibre count data}

Muscle fibre development data obtained from the muscle sections stained using the antibody specific to MHCI (NOQ7.5.4D) are shown in Table 4. Average fibre number per $\mathrm{mm}^{2}$ was not different between groups for either primary or secondary fibres, nor was average fibre CSA. However, muscle weight and muscle CSA
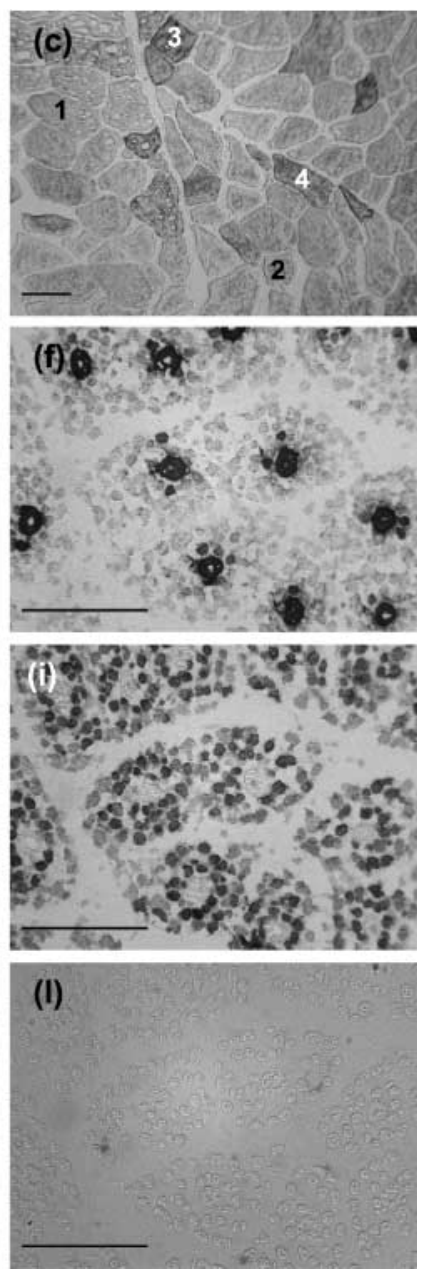

Figure 8 Immunohistochemical staining of the triceps brachii muscle of an adult pig (a-e) and the semitendinosus muscle of a day 90 fetus (f-I). (a) BA-D5 (anti$\mathrm{MHCI} \beta$ ), (b) SC-71 (anti-MHCIla), (c) BF-F3 (anti-MHCllb), (d) BF-35 (anti-MHC except IIx/d), (e) IgG control. Numbers denote the same fibres across serial sections. (f) NOQ7.5.4D (anti-MHCIß), (g) BA-D5 (anti-MHCIß), (h) MY32 (anti-MHCII all), (i) SC-71 (anti-MHClla), (J) BF-F3 (antiMHCllb), (k) BF-35, (I) IgG control. Scale bars represent $50 \mu \mathrm{m}$.

were greater in fetuses from LIG sows. As a consequence, the total number of secondary fibres across the whole muscle was also greater in the fetuses of LIG sows. There was no difference between the LIG and the CTR fetuses in the number of primary fibres, or the secondary:primary fibre ratio. Fetal weight was positively correlated with the mean absolute number of secondary fibres ( $r=0.63$; $P=0.0004)$; however there was no correlation between fetal weight and the relative number of secondary fibres.

\section{Standard SDS-PAGE}

The MHC complement of whole muscle extracts of day 90 fetal tissue was analysed by SDS-PAGE and measured densitometrically. The electrophoretic separation of four different MHC isoforms is shown in Fig. 9. A comparison of their mobilities with bands obtained from rat muscle, adult pig muscle and neonatal pig muscle (Fig. 9) was carried out, and the distribution of $\mathrm{MHC}$ isoforms is shown in Table 5. The fetal MHC isoform was most abundant, followed by embryonic, type Ila and type I $\beta$. There were no differences in relative isoform distribution between fetuses from LIG and CTR sows (Table 5). 
Table 4 Muscle fibre development data (means \pm S.E.M.) for day 90 fetuses from control (CTR) and unilaterally oviduct ligated (LIG) sows $(n=28)$.

\begin{tabular}{|c|c|c|c|}
\hline \multirow[b]{2}{*}{ Parameter } & \multicolumn{2}{|c|}{ Treatment group } & \multirow[b]{2}{*}{$\boldsymbol{P}$} \\
\hline & CTR $(n=14)$ 'Relatively crowded' & LIG $(n=14)$ 'Non-crowded' & \\
\hline Primary fibre no. $/ \mathrm{mm}^{2}$ & $29.5 \pm 1.5$ & $25.8 \pm 1.3$ & 0.073 \\
\hline Primary fibre CSA $\left(\mu \mathrm{m}^{2}\right)$ & $123.5 \pm 5.6$ & $130.4 \pm 4.0$ & 0.33 \\
\hline Secondary fibre no. $/ \mathrm{mm}^{2}$ & $678.7 \pm 16.5$ & $673.3 \pm 18.6$ & 0.83 \\
\hline Secondary fibre CSA $\left(\mu \mathrm{m}^{2}\right)$ & $23.1 \pm 1.5$ & $20.2 \pm 0.5$ & 0.072 \\
\hline ST muscle weight $(\mathrm{g})$ & $1.25 \pm 0.06$ & $1.47 \pm 0.09$ & 0.014 \\
\hline ST muscle CSA $\left(\mathrm{mm}^{2}\right)$ & $47.71 \pm 2.85$ & $58.78 \pm 2.65$ & 0.009 \\
\hline Number total primary fibres & $1394 \pm 81$ & $1480 \pm 57$ & 0.39 \\
\hline Number total secondary fibres & $32,691 \pm 2098$ & $39,628 \pm 2074$ & 0.027 \\
\hline Secondary:primary fibre ratio & $24.01 \pm 1.49$ & $26.80 \pm 0.06$ & 0.13 \\
\hline
\end{tabular}

ST, semitendinosus.
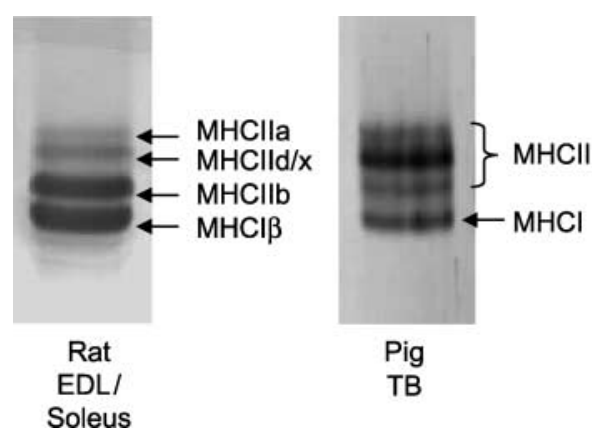

TB

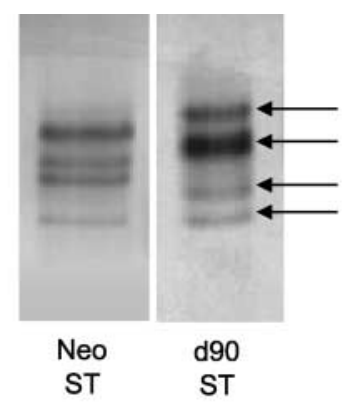

(a) MHC-Embryonic

(b) MHC-Fetal

(c) $\mathrm{MHClla}$

(d) $\mathrm{MHCl} \beta$
Table 5 Myosin heavy chain (MHC) isoform distribution (mean \pm S.E.M.) in day 90 fetal semitendinosus muscle from control (CTR) and unilaterally oviduct ligated (LIG) sows $(n=28)$.

\begin{tabular}{|c|c|c|c|}
\hline \multirow[b]{2}{*}{ Parameter } & \multicolumn{2}{|c|}{ Treatment group } & \multirow[b]{2}{*}{$\boldsymbol{P}$} \\
\hline & $\begin{array}{c}\text { CTR }(n=14) \\
\text { 'Relatively crowded' }\end{array}$ & $\begin{array}{c}\text { LIG }(n=14) \\
\text { 'Non-crowded' }\end{array}$ & \\
\hline Embryonic MHC (\%) & $23.30 \pm 2.37$ & $25.05 \pm 1.18$ & 0.52 \\
\hline Fetal MHC (\%) & $58.61 \pm 2.46$ & $55.46 \pm 1.72$ & 0.30 \\
\hline Type Ila MHC (\%) & $13.26 \pm 2.34$ & $12.66 \pm 0.82$ & 0.81 \\
\hline Type I $\beta$ MHC (\%) & $6.45 \pm 1.12$ & $6.84 \pm 1.14$ & 0.81 \\
\hline
\end{tabular}

\section{In-Gel immunodetection}

In-Gel immunodetection with the MF-20 antibody that recognizes all MHC isoforms, confirmed that the four bands observed on the protein gels were all isoforms of MHC. Various antibodies were used to determine the identification of the four myosin bands. In the day 90 tissue, the band with the greatest mobility (band d) was identified as $\mathrm{MHCl} \beta$ based on reactivity with NOQ7.5.4D. The band with the second greatest mobility (band c) was identified as MHClla based on reactivity with SC-71. Positive bands were not observed using the developmental antibodies NCL-d, NCL-n and BF-45 due to the apparent lack of reactivity of these antibodies with porcine muscle. However, the two upper bands observed in the day 90 samples were tentatively identified as fetal (band b) and embryonic (band a), based on the gel patterns established by Lefaucheur et al. (2001). As expected, these fetal and embryonic bands were not observed in adult tissue.

\section{Discussion}

Based on existing literature, the central hypothesis tested in this study was that increased uterine crowding in early gestation will have important consequences for fetal muscle fibre development of all surviving fetuses.

An ovulation rate of $19.90 \pm 0.36$ for this third parity sow population allowed the possibility of substantially increased uterine crowding compared with the gilts studied by van der Lende et al. (1990). Although this ovulation rate was considerably lower than that reported in other multiparous dam-line sows (Orzechowski 1998, Vonnahme et al. 2002, Town 2004), the number of viable embryos in CTR sows at day 30 (15.1) was similar to these earlier studies. In contrast, unilateral oviduct ligation resulted in a major reduction in the number of embryos at day 30 (9.3) and fetuses at day 90 (9.4), allowing us to test our central hypothesis over a range of uterine crowding that is known to exist in commercial herds. As the proportion of embryos surviving to day 30 , and fetuses surviving to day 90, was higher in the LIG sows, it appears that mechanisms that drive selective reduction in the number of pre-implantation embryos, and match the number of conceptuses in the post-implantation period to functional uterine capacity, were both operative in the CTR sows. 
Consistent with earlier studies (Almeida et al. 2000, Vonnahme et al. 2002), average placental weight was lighter in conceptuses of CTR sows at day 30 and was negatively correlated with the number of viable embryos; however, embryo weight was not different between groups. At day 90 of gestation, both placental weight and fetal weight were lighter in CTR sows, and placental weight was positively correlated with fetal weight. These relationships are consistent with the positive correlation between average placental weight at term and average birth weight seen in our previous studies (Town et al. 2002, $\left.r^{2}=0.76, P<0.001\right)$, and reported by Biensen et al. (1999) and Wilson and Ford (2000). Also, both fetal and placental weight were inversely related to the number of viable fetuses at day 90, in agreement with data on fetal weight reported by Bauer et al. (1998). Collectively, we interpret these data as indicating that day 30 embryos were less sensitive to nutrient limitations than fetuses in later gestation. However, the early limitation in placental size in CTR sows at day 30 ultimately limited fetal development later in gestation, as was borne out by the day 90 data.

Generally, IUGR in animal studies has been defined in terms of fetuses or neonates weighing less than two standard deviations below the mean body weight for gestational age, or more frequently, below the mean body weight of the relevant study population. Whilst statistical definitions of IUGR are useful to classify extremely compromised and 'runted' individuals, the effects of IUGR are likely more complex and probably exist as a gradient of effects of growth restriction within a litter. As part of the central hypothesis tested in the present study, it is important to recognise that the fetuses and neonates chosen for measurement deliberately excluded the extremes of IUGR. Clearly, individuals within the relatively crowded CTR litters would be expected to show even greater IUGR. Indeed, using the classical definition of IUGR as those fetuses falling two standard deviations below the mean body weight of the litter, runt fetuses were present in twelve of the litters from the CTR, compared with only two of the litters from the LIG sows (data not shown).

Based on an analysis of relative organ weights used in previous studies (McMillen et al. 2001), relative heart, lung and spleen weights were unrelated to fetal weight, and relative liver weight was only weakly correlated with fetal weight, whereas relative brain weight showed a strong negative correlation to fetal weight (Fig. 5a). Together with strong negative correlations between brain: liver weight ratio and both fetal weight (Fig. 6a) and placental weight (Fig. 6b), the higher brain:liver weight ratio in fetuses from CTR litters, and the strong positive correlation between brain:liver weight ratio and the number of viable fetuses (Fig. 7), the data indicate detrimental effects of decreased placental size on prenatal development in the present study. Although not as large as the increase in brain:liver weight ratio in IUGR fetuses reported by Bauer et al. (1998, 2002), the increase in the day 90 brain:liver weight ratio from $0.97 \pm 0.04$ in LIG fetuses to $1.17 \pm 0.04$ in CTR fetuses was, nevertheless, associated with a significant decrease in the number of secondary fibres in CTR fetuses.

The existence of limited periods or 'critical windows' of time for cell multiplication and differentiation in different organs and tissues is an essential driver of detrimental long term effects of IUGR. It is generally understood that a growth-retarding stress during the phase of cell proliferation in an organ will cause permanent restriction of that cell population, while a similar stress during the later growth phase may cause a reversible impairment in cell size. This is particularly relevant in the context of muscle fibre development. All available evidence indicates that differentiation of primary and secondary muscle fibres will be completed by day 90 in the pig (Wigmore \& Stickland 1983). Therefore, even if the effects of uterine crowding on muscle fibre numbers are associated with decreased fetal weight at day 90, subsequent fetal growth will not correct the problem of limited numbers of muscle fibres. Evidence that the brain:semitendinosus muscle weight ratio, and the brain:total secondary muscle fibre ratio, were also higher in the CTR sows, is therefore of considerable economic, as well as physiological, significance.

Although the scope of the present experiment did not allow analysis of postnatal growth effects, earlier studies (Handel \& Stickland 1987, Dwyer et al. 1993, 1994) have clearly demonstrated reduced postnatal growth potential due to quantitative effects on fetal muscle development through maternal undernutrition. The results of the present study extend the findings of previous work in the pig in which both naturally occurring IUGR within a litter (Aberle 1984) and nutritional manipulation during gestation (Dwyer et al. 1994) preferentially affected secondary muscle fibre development.

A clearer understanding of the origin and extent of effects of uterine crowding on muscle fibre development is clearly important and appropriate immunohistochemical and gel electrophoresis technologies for identifying crowding effects on muscle fibre development were established as part of the present study. In an extension of the methodology used by Lefaucheur et al. (2002), In-Gel immunodetection was used in combination with immunohistochemistry to further elucidate the MHC isoforms present in porcine fetal muscle tissue. In-Gel immunodetection (data not shown) with the MF-20 antibody that recognizes all $\mathrm{MHC}$ isoforms confirmed that the bands observed by silver staining after gel electrophoresis were all isoforms of MHC. Consistent with the findings of Lefaucheur et al. (2001), the isoform that displayed the greatest electrophoretic mobility was identified as MHCI 3 . Using immunohistochemistry, positive reactivity was also observed using BAD-5 (specific staining for $\mathrm{MHCl}$ ) for both adult triceps brachii tissue and fetal day 90 semitendinosus tissue, and NOQ7.5.4D also showed specific staining for $\mathrm{MHCl} \beta$ in day 90 semitendinosus tissue (Fig. 8). As reported by Lefaucheur et al. (2001) using 
newborn piglet tissue, none of the primary fibres reacted with the antibody $\mathrm{F} 88.12 \mathrm{~F} 8$ (specific to $\mathrm{MHCl} \alpha$ ) in day 90 semitendinosus tissue, confirming that $\mathrm{MHCl} \alpha$ is not present in the semitendinosus muscle until after birth in the pig.

Using immunohistochemistry, positive staining was observed for MHClla (using SC-71) for both day 90 and adult tissue and expression of this isoform was confirmed using In-Gel immunodetection. In contrast to Lefaucheur et al. (2001) who reported that all three adult MHCII isoforms (i.e. Ila, IIx and IIb) co-migrated using standard SDS-PAGE techniques, three fast MHC isoforms were observed in adult tissue in the present study and a total of four bands in these adult tissue samples is in agreement with the immunohistochemical evidence for the $I \beta$, Ila, Ilb and IIx isoforms. In the case of day 90 fetal tissue, it is likely that band c (Fig. 9) is solely MHClla, as there was no evidence for the presence of Ilb or IIx fibres based on the immunohistochemical results.

Based on the relative electrophoretic mobilities of the two upper bands observed in the day 90 samples by gel electrophoresis (Fig. 9), they were tentatively identified as fetal (band b) and embryonic (band a), described by Lefaucheur et al. (2001). Based on this definition, the fetal $\mathrm{MHC}$ isoform was most abundant, followed by embryonic, -Ila and - $\mid \beta$. Interestingly, developmental antibodies NCL-d, NCL-n and BF-45 that have been used in studies of tissue from other species (NCL-d, Putman et al. 2000; NCL-n, Ecob-Prince et al. 1989; BF-45, Schiaffino et al. 1988, Putman et al. 2003) do not appear to recognise the corresponding porcine isoforms by either immunohistochemical or In-Gel immunodetection methods. From the perspective of effects of crowding in utero and IUGR on myogenesis, there were no qualitative differences in the patterns of isoform distribution between fetuses from LIG and CTR sows, confirming previous results from our group (Town 2004). From a commercial perspective, this suggests that the size rather than the quality of the developing muscle is most affected in IUGR fetuses.

In summary, the present results are consistent with the central hypothesis tested, that even moderate crowding of the uterus at day 30 of gestation compromises subsequent fetal development and, specifically, the number of fetal secondary muscle fibres. In prolific sow genotypes, increased uterine crowding will exert even more severe effects on fetal muscle development and consequently on postnatal growth potential. These data provide important insights into the biological basis of variability in postnatal growth performance that has become an important economic concern for the swine industry.

\section{Acknowledgements}

The authors gratefully acknowledge the Swine Research and Technology Centre and the University of Alberta Metabolic Unit staff members for care of the animals, S. Shostak for help with radioimmunoassays, R O'Donoghue for help with necropsies and immunohistochemisty, J Pearcey and I M MacLean for assistance with immunohistochemistry and SDS-PAGE and Dr X J Sun of the Alberta Cross Cancer Institute Cellular Imaging Facility for help with image acquisition. The authors would also like to thank $\operatorname{Dr} \mathrm{S}$ Schiaffino for providing the purified antibody BF-35. This research was financially supported by the Alberta Agricultural Research Institute, NSERC, Alberta Pork and Genex Swine Group. S C Town was the recipient of an FS Chia PhD Scholarship from the University of Alberta. C T Putman is a Medical Scholar of the Alberta Heritage Foundation for Medical Research and G R Foxcroft is supported through appointment to a Canada Research Chair in Swine Reproductive Physiology (www.chairs.gc.ca).

\section{References}

Aberle ED 1984 Myofiber differentiation in skeletal muscle of newborn runt and normal weight pigs. Journal of Animal Science $\mathbf{5 9}$ $1651-1656$.

Adams PH 1971 Intra-uterine growth retardation in the pig: II. Development of the skeleton. Biology of the Neonate 19 341-353.

Almeida FRCL, Kirkwood RN, Aherne FX \& Foxcroft GR 2000 Consequences of different patterns of feed intake during the estrous cycle in gilts on subsequent fertility. Journal of Animal Science $\mathbf{7 8}$ 1556-1563.

Ashworth CJ \& Pickard AR 1998 Embryo survival and prolificacy. In Progress in Pig Science, pp 302-325. Eds J Wiseman, MA Varley \& JP Chadwick. Nottingham: Nottingham University Press, UK.

Bauer R, Walter B, Hoppe A, Gaser E, Lampe V, Kauf E \& Zwiener U 1998 Body weight distribution and organ size in newborn swine (Sus scrofa domestica) - a study describing an animal model for asymmetrical intrauterine growth retardation. Experimental and Toxicologic Pathology 50 59-65.

Bauer R, Walter B, Bauer K, Klupsch R, Patt S \& Zwiener U 2002 Intrauterine growth restriction reduces nephron number and renal excretory function in newborn piglets. Acta Physiologica Scandinavica 176 83-90.

Bazer FW, Clawson AJ, Robison OW \& Ulberg LC 1969a Uterine capacity in gilts. Journal of Reproduction and Fertility $\mathbf{1 8}$ 121-124.

Bazer FW, Robison OW, Clawson AJ \& Ulberg LC 1969b Uterine capacity at two stages of gestation in gilts following embryo superinduction. Journal of Animal Science 29 30-34.

Biensen NJ, Wilson ME \& Ford SP 1998 The impact of either a Meishan or a Yorkshire uterus on Meishan or Yorkshire fetal and placental development to days 70,90 and 110 of gestation. Journal of Animal Science 76 2169-2176.

Biensen NJ, Haussmann MF, Lay Jr DC, Christian LL \& Ford SP 1999 The relationship between placental and piglet birth weights and growth traits. Animal Science $\mathbf{6 8} 709-715$.

Clelland AK \& Stickland NC 2001 Porcine satellite cells from large and small siblings respond differently to in vitro conditions. Basic Applied Myology 11 45-49.

Cooper JE, John M, McFadyen IR \& Wootton R 1978 Early appearance of 'runting' in piglets. Veterinary Record 102 529-530.

Dwyer CM, Madgwick AJA, Crook AR \& Stickland NC 1992 The effect of maternal undernutrition on the growth and development of the guinea pig placenta. Journal of Developmental Physiology 18 295-302.

Dwyer CM, Fletcher JM \& Stickland NC 1993 Muscle cellularity and postnatal growth in the pig. Journal of Animal Science $\mathbf{7 1}$ 3339-3343.

Dwyer CM, Stickland NC \& Fletcher JM 1994 The influence of maternal nutrition on muscle fiber number development in the porcine fetus and on subsequent postnatal growth. Journal of Animal Science 72 911-917. 
Dziuk PJ 1968 Effect of number of embryos and uterine space on embryo survival in the pig. Journal of Animal Science 27 673-676.

Ecob-Prince M, Hill M \& Brown W 1989 Immunocytochemical demonstration of myosin heavy chain expression in human muscle. Journal of Neurological Science 91 71-78.

Fazarinc G, Majdic G, Lorger J, Pogacnik A \& Bavdek SV 1995 Combined histochemical and immunohistochemical determination of three muscle fibre types in a single section of porcine skeletal muscle. European Journal of Histochemistry 39 309-316.

Fenton FR, Bazer FW, Robison OW \& Ulberg LC 1970 Effect of quantity of uterus on uterine capacity in gilts. Journal of Animal Science 31 104-106.

Flecknell PA, Wootton R, John M \& Royston JP 1981 Pathological features of intra-uterine growth retardation in the piglet: differential effects on organ weights. Diagnostic Histopathology 4 295-298.

Ford SP \& Youngs CR 1993 Early embryonic development in prolific Meishan pigs. Journal of Reproduction and Fertility Supplement $\mathbf{4 8}$ $271-278$.

Foxcroft GR 1997 Mechanisms mediating nutritional effects on embryonic survival in pigs. Journal of Reproduction and Fertility Supplement 52 47-61.

Hämäläinen N \& Pette D 1996 Slow to fast transitions in myosin expression of rat soleus muscle by phasic high-frequency stimulation. FEBS Letters 399 220-222.

Handel SE \& Stickland NC 1987 Muscle cellularity and birthweight. Animal Production 44 311-317.

Hegarty PVJ \& Allen CE 1978 Effect of pre-natal runting on the postnatal development of skeletal muscle in swine and rats. Journal of Animal Science 46 1634-1640.

Knight JW, Bazer FW, Thatcher WW, Franke DE \& Wallace HD 1977 Conceptus development in intact and unilaterally hysterectomized-ovariectomized gilts: interrelations among hormonal status, placental development, fetal fluids and fetal growth. Journal of Animal Science 44 620-637.

Lefaucheur L, Edom F, Ecolan P \& Butler-Browne GS 1995 Pattern of muscle fiber type formation in the pig. Developmental Dynamics $20327-41$

Lefaucheur L, Hoffman R, Okamura C, Gerrard D, Léger JJ, Rubinstein N \& Kelly A 1997 Transitory expression of alpha cardiac myosin heavy chain in a subpopulation of secondary generation muscle fibers in the pig. Developmental Dynamics 210 $106-116$.

Lefaucheur L, Ecolan P, Lossec G, Gabillard J-C, Butler-Browne GS \& Herpin P 2001 Influence of early postnatal cold exposure on myofiber maturation in pig skeletal muscle. Journal of Muscle Research and Cell Motility 22 439-452.

Lefaucheur L, Ecolan P, Plantard L \& Gueguen N 2002 New insights into muscle fiber types in the pig. Journal of Histochemistry and Cytochemistry 50 719-730.

van der Lende T \& de Jager D 1991 Death risk and preweaning growth rate of piglets in relation to the within-litter weight distribution at birth. Livestock Production Science 28 73-84.

van der Lende T, Hazeleger W \& de Jager D 1990 Weight distribution within litters at the early foetal stage and at birth in relation to embryonic mortality in the pig. Livestock Production Science $\mathbf{2 6}$ $53-65$.

McMillen IC, Adams MB, Ross JT, Coulter CL, Simonetta G, Owens JA, Robinson JS \& Edwards LJ 2001 Fetal growth restriction: adaptations and consequences. Reproduction 122 195-204.
Orzechowski KJ 1998 Comparison of endocrine regulators of metabolism and postweaning reproduction in primiparous and multiparous sows. MSc Thesis, University of Manitoba, Winnipeg, Canada.

Père M-C, Dourmand J-Y \& Etienne M 1997 Effect of number of pig embryos in the uterus on their survival and development and on maternal metabolism. Journal of Animal Science 75 1337-1342.

Putman CT, Düsterhöft S \& Pette D 2000 Satellite cell proliferation in low frequency-stimulated fast muscle of hypothyroid rat. American Journal of Physiology - Cell Physiology 279 C682-C690.

Putman CT, Kiricsi M, Pearcey J, MacLean IM, Bamford JA, Murdoch GK, Dixon WT \& Pette D 2003 AMPK activation increases uncoupling protein-3 expression and mitochondrial enzyme activities in rat muscle without fibre type transitions. Journal of Physiology 551 $169-178$.

Royston JP, Flecknell PA \& Wootton R 1982 New evidence that the intra-uterine growth-retarded piglet is a member of a discrete subpopulation. Biology of the Neonate 42 100-104.

Schiaffino S, Gorza L, Pitton G, Saggin L, Ausoni S, Satore S \& Lomo T 1988 Embryonic and neonatal myosin heavy chain in denervated and paralyzed rat skeletal muscle. Developmental Biology 127 $1-11$.

Schiaffino S, Gorza L, Satore S, Saggin L, Ausoni S, Vianello M, Gundersen K \& Lomo T 1989 Three myosin heavy chain isoforms in type 2 skeletal muscle fibres. Journal of Muscle Research and Cell Motility 10 197-205.

Town SC 2004 Patterns of prenatal loss: implications for placental and fetal development. PhD Thesis, University of Alberta, Edmonton, Canada.

Town SC, Patterson JL \& Foxcroft GR 2002 Evidence for uterine effects on fetal development in the pig. Journal of Animal Science Supplement 80797 (Abstract).

Vallet JL 2000 Fetal erythropoiesis and other factors which influence uterine capacity in swine. Journal of Applied Animal Research 17 $1-26$.

Vallet JL, Klemcke HG, Christenson RK \& Pearson PL 2003 The effect of breed and intrauterine crowding on fetal erythropoiesis on day 35 of gestation in swine. Journal of Animal Science $\mathbf{8 1}$ $2352-2356$.

Vonnahme KA, Wilson ME, Foxcroft GR \& Ford SP 2002 Impacts on conceptus survival in a common swine herd. Journal of Animal Science 80 553-559.

Widdowson EM 1971 Intra-uterine growth retardation in the pig: I. Organ size and cellular development at birth and after growth to maturity. Biology of the Neonate 19 329-340.

Wigmore PMC \& Stickland NC 1983 Muscle development in large and small pig fetuses. Journal of Anatomy 137 235-245.

Wilson ME \& Ford SP 2000 Effect of estradiol-17 $\beta$ administration during the time of conceptus elongation on placental size at term in Meishan pigs. Journal of Animal Science 78 1047-1052.

Wootton R, Flecknell PA, Royston JP \& John M 1983 Intrauterine growth retardation detected in several species by non-normal birthweight distributions. Journal of Reproduction and Fertility 69 659-663.

Received 31 October 2003

First decision 8 January 2004

Revised manuscript received 3 May 2004

Accepted 29 June 2004 